Goldschmidt 2021 Abstract

https://doi.org/10.7185/gold2021.6720

\section{Absolute seasonality reconstructions from clumped isotope analyses in carbonate archives}

NIELS J. DE WINTER ${ }^{1,2}$, INIGO A MÜLLER ${ }^{1}$, ILJA JAPHIR KOCKEN ${ }^{1}$, TOBIAS AGTERHUIS ${ }^{1}$ AND MARTIN ZIEGLER $^{1}$

${ }^{1}$ Utrecht University

${ }^{2}$ Vrije Universiteit Brussel

Presenting Author: n.j.dewinter@uu.nl

Reconstructions of past greenhouse climates hold the key to understanding a warmer future climate caused by anthropogenic greenhouse gas emissions. Recent studies of carbonate archives have significantly advanced our understanding of dissimilar climate states across the Cenozoic (e.g. Tierney et al., 2020, Westerhold et al., 2020). Many long-term climate reconstructions are based on assumptions, such as negligible seasonal bias in climate archives and well-known, seasonally invariant seawater compositions (e.g. $\delta^{18} \mathrm{O}_{\mathrm{sw}}$ and $\mathrm{Mg} / \mathrm{Ca}$ ). However, studies of modern carbonate producers show that these assumptions do not necessary hold true, and they may bias past climate reconstructions (de Winter et al., 2020a; Caldarescu et al., 2021). Clumped isotope analyses yield temperature reconstructions independent of the composition of the precipitation fluid (e.g. seawater; e.g. Eiler, 2007). Recent advances now allow clumped isotope-based seasonality reconstructions from accretionary carbonate archives (e.g. fossil mollusks), potentially solving both seasonal and compositional biases in climate reconstructions (de Winter et al., 2020a; b; Caldarescu et al., 2021). Here, we outline the statistical and analytical techniques required to reconcile the larger sample size demand of the clumped isotope method with the comparatively small sample size required to analyze subannual profiles through fossil carbonates. We present some of the first applications of this new reconstruction technique on fossil mollusks from past periods analogues to future climate scenarios, such as the Pliocene Warm Period and the Late Cretaceous. Finally, we discuss the implications of these high-resolution climate reconstructions for our understanding of past greenhouse climates.

\section{References}

Caldarescu, D. E.; et al., Geochimica et Cosmochimica Acta 2021, 294, 174-191.

de Winter, N. et al. Climate of the Past Discussions 2020a, 152.

de Winter, N. J. et al., Nature Communications in Earth and Environment in review (preprint 2020b). https://doi.org/10.21203/rs.3.rs-39203/v2.

Eiler, J. M. Earth and Planetary Science Letters 2007, 262 (3), 309-327.

Tierney, J. E. et al. Science 2020, 370 (6517).

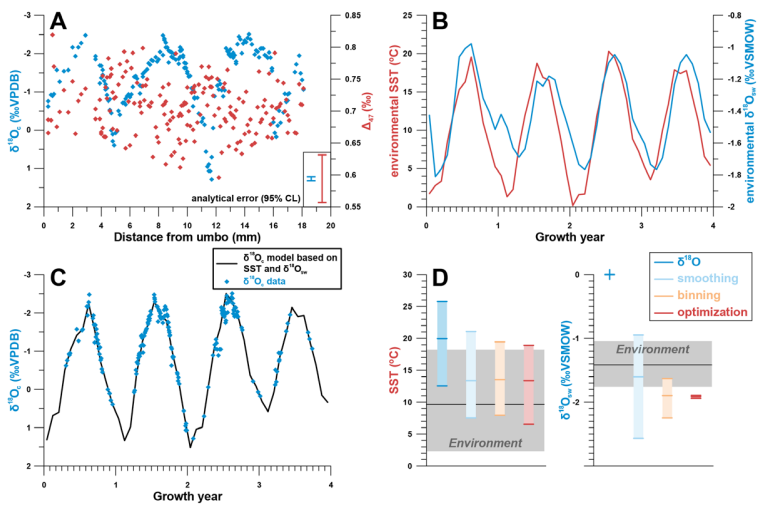

